\title{
A formação do pedagogo do século XXI, quebrando paradigmas
}

\section{The educational backround of the 21st century teacher, breaking paradigms}

\author{
Paulo Jorge Medeiros ${ }^{1 *}$, Rosangela Trabuco Malvestio da Silva ${ }^{1}$
}

\section{RESUMO}

Este texto tem por objetivo identificar os desafios da profissão do Pedagogo na atualidade, afim se superar o preconceito relacionado ao professor homem e o ensino na Educação Infantil e Anos Iniciais. É um estudo pautado na pesquisa qualitativa, fundamentado em estudo bibliográfico com base no materialismo histórico, na busca de dialogar com os autores que discutem a temática. Em um no primeiro momento realiza um breve histórico sobre a profissão do pedagogo, entendendo como se deu a ascensão da mulher no campo de trabalho do magistério no Brasil, assim como o contexto histórico que este fato aconteceu, ao passo que esse processo levou o afastamento do homem do ensino voltado às crianças menores. Em um Segundo momento discute-se o a reinserção do homem na profissão de pedagogo na Educação Infantil e nos Anos Iniciais do Ensino Fundamental, contribuindo para a superação do paradigma que envolve o homem e a pedagogia. As reflexões realizadas neste estudo contribuem para desvelar algumas ideias que permeiam a sociedade e o senso comum no que tange ao trabalho do professor homem nas escolas da Educação Infantil e do Ensino Fundamental dos Anos Iniciais.

Palavras-chave: Pedagogo; Educação infantil; Ensino Fundamental; Homem na Pedagogia;

\begin{abstract}
The purpose of this paper is to identify the challenges facing the profession of the Pedagogue today, in order to overcome the prejudice related to the male teacher and the teaching in Kindergarten and Early Childhood Education.It is a study based on qualitative research, founded on a bibliographical study based on historical context, in an attempt to dialogue with authors who discuss the topic. Firstly, a brief history about the pedagogue's profession is presented, understanding how the ascension of women in the teaching field in Brazil happened, as well as the historical context that this fact happened, while this process led to the removal of men from the teaching of younger children. Secondly, we discuss the reinsertion of men in the pedagogical profession in Children's Education and in the First Years of Elementary School, contributing to overcoming of the paradigm that involves men and pedagogy. The analysis done in this study contributes to unveil some ideas that permeate society and common sense regarding the work of the male teacher in Early Childhood Education and Elementary School.
\end{abstract}

Keywords: Pedagogue; Early Childhood Education; Elementary School; Man in Pedagogy;

\footnotetext{
${ }^{1}$ Universidade estadual do Paraná - Unespar.

* E-mail: paulojorge436@gmail.com
} 


\section{INTRODUÇÃO}

A questão do homem como professor na Educação Infantil e no Ensino Fundamental Anos Iniciais, ainda é um tabu a ser superado, pois a mulher assumiu ao longo da história um protagonismo no papel de educadora nesta etapa de ensino. Esta realidade se caracterizou historicamente por vários aspectos, como por exemplo, o fato do magistério ser a única profissão permitida no início do século XX para as mulheres, o que é fruto da constituição de uma sociedade patriarcal. Esta situação, aliada aos baixos pisos salariais, fez com que o homem se afastasse gradativamente da profissão.

Porém no mundo contemporâneo a relação do trabalho se modificou, de modo que não se tem mais a separação entre o que é trabalho de homem e o que é trabalho de mulher. Percebese que nas escolas de Educação Infantil e dos Anos Iniciais, o trabalho é realizado predominado por mulheres. Com as transformações do mundo do trabalho, os homens estão voltando para a pedagogia, e este retorno deixa muitas lacunas, sendo necessário estudos e reflexões acerca do tema. As investigações sobre essa problemática teve início durante a graduação na disciplina "Estágio na Educação Infantil", na qual percebeu-se que não haviam profissionais homens nesse campo de trabalho, e a participação dos acadêmicos homens foram limitadas ao espaço administrativo. Já no estágio do Ensino Fundamental, percebeu-se que, o homem também não aparece na prática docente, porém o mesmo está presente nas atividades do campo administrativo como na secretaria da escola. Dessa forma, surge à pergunta: $O$ homem pode ser professor na Educação Infantil e nas séries iniciais do Ensino Fundamental? É importante inferir que estes são habilitados para tal no curso de Pedagogia, mas nas escolas os professores homens estão pouco presente nessa fase da educação.

Dessa forma, a pesquisa não visa discutir quem realiza o melhor trabalho de educar, mas lançar reflexões acerca da problemática, pois a pedagogia é um campo de trabalho para ambos os sexos, sendo necessário superar o preconceito de que homem não pode ser professor da Educação Infantil e nos Anos Iniciais, questionando o pensamento socialmente construído de que só a mulher pode ser professora nesta etapa de ensino.

O objetivo deste estudo foi identificar os desafios da profissão do Pedagogo na Educação Infantil e nos Anos Iniciais do Ensino Fundamental, a fim refletir acerca do preconceito relacionado ao homem e a pedagogia na atualidade. A metodologia utilizada é a pesquisa qualitativa, fundamentada no estudo bibliográfico com base no materialismo histórico, que busca dialogar com os autores que discutem a temática. Para atingir o objetivo proposto, em um primeiro momento realiza um breve histórico sobre a profissão do pedagogo. A pesquisa buscou entender como se deu a ascensão da mulher no campo de trabalho do magistério no Brasil, assim como entender o contexto histórico que o fato aconteceu. 
Para entender esse processo que envolve mulher e o magistério é proposto discutir o processo de "feminização do magistério". Depreende-se que o papel da mulher na pedagogia foi construído socialmente e foi sendo reforçado ao longo do tempo, ao passo que esse processo levou o afastamento do homem do ensino voltado às crianças menores. Ao final deste estudo, esperase contribuir para a superação do preconceito existente na sociedade atual, nessa relação do homem com a pedagogia. Sendo assim, por meio de um contexto histórico sobre a educação no Brasil, a pesquisa contribuiu para a compreensão do problema, que foi constituído ao longo da história e o hoje se apresenta como um tabu.

\section{BREVE HISTÓRICO DA PROFISSÃO PEDAGOGO}

Para entender essa problemática é preciso fazer uma breve análise da educação na história da humanidade, para compreender a relação do profissional homem na atualidade e o desenvolvimento da pedagogia.

Na pré-história ou comunidades tribais, não havia necessidade de escolas, pois o conhecimento era passado de pai para filho, conforme a prática (caça, pesca, cultivo de alimentos). Com o desenvolvimento dos instrumentos de trabalho os homens deixaram de ser nômades e se estabeleceram em terras, desenvolvendo a agricultura. Os homens precisaram de um código escrito para manter a organização e a comunicação entre os grupos. Conforme Aranha (2006), os Fenícios foram os primeiros a desenvolverem a escrita, isso, com finalidade de facilitar as negociações, mas esse saber era restrito. Dentre os povos conhecidos, haviam os escribas, mas esses não tinham o papel de professor, pois eram de famílias ricas e o acesso à escrita era para relatar os acontecimentos diários, como também os cargos públicos eram destinados a essa especialidade.

$\mathrm{Na}$ Grécia antiga com o pensamento filosófico, começou-se a pensar na necessidade de se ter uma educação para os indivíduos (mas não era para todos), assim se deu o advento da pedagogia, que "surge originalmente do latim pedagogus, que provém da palavra grega paidagogos (pais): país, pedá, paidós (criança) + agein, agogos (condutor, dirigente)” [...] (BUENO, 1966. apud Santos, 2017. p. 67). De acordo com Santos (2017) o pedagogo era um escravo responsável por conduzir a criança até o conhecimento. "Cabia a ele levar as crianças até o local do conhecimento, mas não necessariamente era sua função, de início, instruí-las. Essa segunda etapa ficava por conta do preceptor (aquele que toma a dianteira)" (SANTOS, 2017. p. $68)$.

Dessa forma, a pedagogia estava presente na vida social do homem, mas o seu significado não era o mesmo de hoje em dia, ou seja, a pedagogia não era diretamente ligada a educação. Como afirma Abbagnano (2007): 
[...] na Antigüidade clássica a pedagogia não tinha a dignidade de ciência autônoma, mas era considerada parte da ética ou da política, e por isso elaborada unicamente em vista do fim que a ética ou a política propunham ao homem. Por outro lado, os expedientes ou os meios pedagógicos só eram estudados em relação à primeira educação, ministrada na infância, portanto às mais elementares aquisições (ler, escrever, contar). Assim, até certa altura, a reflexão pedagógica é dividida em dois ramos isolados: um de natureza puramente filosófica, elaborado com vistas aos fins propostos pela ética, e outro de natureza empírica ou prática, elaborado com vistas à preparação primeira e elementar da criança para a vida (ABBAGNANO, 2007, p. 748).

Entretanto, nesse período histórico o foco da pedagogia não eram voltados a educação, mas estavam ligados a auxiliar as crianças para as relações de sua vida, sendo assim, os estudos eram voltados para a filosofia e a ética e para a natureza. Em função disso, Aranha (2006), aponta que o pedagogo na antiguidade era o escravo que auxiliava a criança no seu desenvolvimento.

Na Idade Média a educação e os métodos pedagógicos era uma responsabilidade da igreja Católica, pois o objetivo era formar um individuo cristão. Com a chegada da era Moderna, uma nova classe social estava em ascensão: "a burguesia". Houve a necessidade de a sociedade repensar novas ideologias para a educação. A transição da Idade Média para o Capitalismo trouxe para a educação os autores clássicos, que apontam a educação como um campo de mudanças para a sociedade.

\begin{abstract}
A partir de Comênio, a experiência pedagógica do Ocidente foi-se enriquecendo e aprofundando, com as tentativas de achar novos métodos educacionais. As obras de Locke. Rousseau, Pestalozzi, Frôebel são muito importantes desse ponto de vista, inclusive por terem esses autores combinado os métodos educacionais, com as novas concepções filosóficas que iam surgindo pouco a pouco. Assim, podemos dizer que Locke representa a P. do empirismo; Rousseau, a P. do iluminismo; Pestalozzi, a P. do criticismo; e Frôebel. (sic) a do romantismo (ABBAGNANO, 2007, p. 748).
\end{abstract}

Nesse sentido, as transformações da sociedade fez com que se pensasse a pedagogia para a educação, pois com todas essas mudanças, vale ressaltar que uma nova classe social estava em ascendência. Dessa forma, foi necessário que a burguesia tivesse um método para educar seus filhos. Sendo assim, alguns autores que desenvolveram o pensamento sobre as teorias pedagógicas no início da era capitalista merecem destaque.

Na interpretação de Boto (2007), o escritor humanista Erasmo de Roterdã (1466-1536), apresentava ainda no período na Renascença uma nova forma de se educar as crianças, ou seja, formar o novo homem que administraria a sociedade. John Locke (1632-1704) trouxe para a educação suas contribuições, em que apontou a criança como um "papel em branco" que precisava ser educada para a vida em sociedade.

Diniz et al. (2018) destacam que Jean-Jacques Rousseau (1712-1778) repensou a educação daquele momento histórico, apontando a necessidade de se pensar a educação, para que os alunos conquistasse sua independência, e assim, realizar suas escolhas a partir do seu 
conhecimento, ou seja, a educação era a autonomia para o aluno. Em sua obra Emílio ${ }^{2}$ ou da Educação (1762) Rousseau, apresenta uma mudança na forma de entender a educação, destacando a importância do preceptor para a educação da criança.

De acordo com Boto (2010) é com a obra de Rousseau que a educação passou a ser considerada importante para os indivíduos, sendo que a mesma acontece por período, ou seja, é a partir dessas ideias que o autor classifica do desenvolvimento da criança por estágios. Dessa forma, a obra com os ideais iluministas de Rousseau passou a ser considerado um marco para a História da Educação.

A partir dessa reflexão sobre Rousseau, pode-se dizer que Friedrich Froebel (17821852), seguiu os passos deste autor para elaborar seu pensamento sobre a educação. Conforme Arce (2002) Froebel apontou o educador como um observador de todo o processo de aprendizagem dos alunos. Contudo a autora ressalta que em 1840, Froebel desenvolveu o "Kindergarten", ou melhor, o "Jardim de Infância". Com uma teoria voltada para e educação, o autor trouxe as mulheres para a Educação Infantil, de modo que eram consideraras educadoras natas, chamada pelos mesmos de jardineiras que eram responsáveis pelo desenvolvimento das crianças.

Aranha (2006) escreve que no Brasil a pedagogia chega com os "Jesuítas", ainda no período de colonização, com o objetivo de catequizar os índios. Dessa forma, a pedagogia estava articula ao um conjunto de regras, chamado de Ratio Studiorum, a qual seu objetivo era formar um homem cristão.

Os avanços na sociedade brasileira só começam acontecer a partir de (1808) com a vinda da família Real de Portugal (fugidos da guerra de Napoleão). Sua chegada trouxe para a sociedade brasileira várias melhorias dentre elas o Banco do Brasil, a Impressa Régia, Jardim Botânico, Escola de cirurgia em Salvador, Museu Nacional, Biblioteca Pública e a Universidade - isto para atender aos interesses dos membros da corte recém chegados ao país.

O Brasil Império trouxe transformações para a sociedade brasileira, consequentemente fez a educação também se modificar. Mesmo assim, a educação não era uma preocupação e nem prioridade, não se tinha métodos pedagógicos para o ensino, esses eram copiados as ideias europeias. Vale ressaltar que no período da Proclamação da República (1889) em diante é que a educação sofreu transformações significativas, e a relação do homem com a pedagogia foi se modificando.

2 Rousseau descreve a condição da criança, ao mesmo tempo em que inventa um menino imaginário, que deveria ser educado de acordo com os critérios da natureza. A educação do menino Emílio pode ser compreendida como libelo contra o severo tratamento oferecido às crianças de verdade - tanto nas famílias como nos colégios (BOTO, 2010. p. 209). 
Segundo Araújo e Cunha (2013), desde a chegada da pedagogia no Brasil até o final do século XIX, a mesma foi conduzida e pensada como uma profissão para o homem, o grande exemplo de formação de caráter e o modelo a ser seguido. $\mathrm{O}$ acesso à educação para a mulher foi negado por um longo período histórico, pois seu papel social era cuidar da família: lavar, bordar, cuidar dos filhos e da casa.

Sobre o desenvolvimento da profissão docente no Brasil, com base em Louro (1997) entende-se que desde sua origem a escola brasileira foi construída e conduzida por mestres, a qual a autora se utiliza da palavra no masculino, para se referir aos homens religiosos, que possuíam as principais representações para serem professores, e são elas;

\footnotetext{
Modelos de virtudes, disciplinados disciplinadores, guias espirituais, conhecedores das matérias e das técnicas de ensino, esses primeiros mestres devem viver a docência como um sacerdócio, como uma missão que exige doação. Afeição e autoridade, bom senso, firmeza e bondade, piedade e saber profissional são algumas das qualidades que lhes são exigidas (LOURO, 1997. p. 93).
}

Vale destacar, que a sociedade não é algo pronta e acabada, e sim está em constante mudança. Com o passar do tempo essas representações foram se modificando. Partindo do ponto de vista da mudança social, Louro (1997) destaca que na foi segunda metade do século XIX, com o processo de urbanização do Brasil, ocorreram algumas mudanças na sociedade e as mulheres conseguem o acesso à escola e à educação, o que fez muitas chegarem à escola não apenas alunas, mas também professoras.

\subsection{PROFISSÃO PROFESSORA: A MULHER NO MERCADO DE TRABALHO}

As transformações causadas pelo processo de industrialização ainda no século XIX geraram mudanças na economia e na sociedade brasileira. Na interpretação de Apple (1998) todas essas mudanças foram fundamentais para lançar a mulher para o mercado de trabalho, e o magistério era a alternativa. Em função disso, Apple (1998) afirma que a classe social foi um dos pontos primordiais para que a mulher entrasse no campo de trabalho do magistério, pois esse era uma oportunidade que "Elevava o status, sobretudo das jovens da classe trabalhadora que demonstravam algum grau de habilidade acadêmica. As condições de trabalho, embora não fossem nenhuma maravilha, eram nitidamente melhor." (APPLE, 1988, p. 21).

Dessa forma, o autor escreve que se o magistério se tornou feminino foi porque os homens o abandonaram. Apple (1988, p. 16) destaca que a chegada da mulher no campo de trabalho docente ficou conhecida pelo uso do termo "feminização do magistério". Entende-se que as mudanças da sociedade aproximaram as mulheres do magistério, que passou a ser visto como 
uma profissão onde a mulher poderia conciliar as tarefas domésticas, o cuidado com a família e o trabalho na escola.

Este pensamento acarretou também um acúmulo de trabalho para a mulher, pois neste momento histórico, além dos afazeres domésticos, ela também teria as atividades decorrentes de sua atividade docente. Este é um dado relevante e tem reflexo nos dias atuais. Segundo a Agência Brasil (2017), atualmente as mulheres trabalham, em média, 7,5 horas a mais que os homens por semana devido à dupla jornada, que inclui tarefas domésticas e trabalho remunerado.

A entrada da mulher na escola como professora, mais do que mudar o cárter da profissão do magistério, também alterou a docência.

Com a entrada numerosa de mulheres na carreira docente, esta prática também passou a ser ressignificada ganhando moldes femininos que refletem a necessidade do cuidado, do amor e do afeto para a educação das crianças que passam a ser vistas como filhos e filhas destas mulheres que tem tanto carinho a oferecer em virtude de suas características consideradas naturais (ARAÚJO, CUNHA, 2013. p.11248).

Desse modo, cada vez mais o papel da mulher como professora, vai se aproximando de suas atividades diárias, sendo assim, o magistério foi considerado a profissão ideal para a mulher, pois como é mãe, também é uma educadora nata. Todo esse processo também teve como resultado o afastamento do homem da educação Infantil e dos Anos Iniciais do Ensino Fundamental, acarretando o achatamento do salário do profissional da educação. Os homens que precisavam manter suas famílias acabaram desistindo da carreira do magistério.

Para Demartini e Antunes (1993) o salário de professor não era o dos melhores, assim os homens abandonaram a profissão, para trabalhar em outras áreas que fossem mais rentáveis, garantindo o sustento da família. Vale destacar que o magistério era uma forma de complementar a renda familiar. "A professora é em regra casada e com o esposo divide o peso dos encargos de família. Raras vezes a professora é, entre nós, a responsável pelas despesas domésticas". (DEMARTINI, ANTUNES. 1993. p. 7) ${ }^{3}$.

O estudo de Demartini e Antunes (1993) mostra que ao passo que os homens abandonaram a sala de aula, mas não deixaram de vez o ambiente escolar, pois “[...] deixam de ser professores para se tornarem diretores, supervisores, formadores de professores, delegados de ensino, chefes da instrução públicas etc. (DEMARTINI, ANTUNES. 1993. p.12). A mulher foi colocada a posição de educadora nata, e que essa justificativa se estabelece para impor que o papel

3 Conforme o Instituto Brasileiro de Geografia e Estatística (IBGE), revela que o número de mulheres que são responsáveis financeiramente pelos domicílios vem crescendo a cada ano e já chega a 34,4 milhões. Isso significa que quase a metade das casas brasileiras são chefiadas por mulheres; situação bem diferente da que era vista alguns anos án (https://www.correiobraziliense.com.br/app/noticia/economia/2020/02/16/internas_economia,828387/mul heres-sao-responsaveis-pela-renda-familiar-em-quase-metade-das-casa.shtml). 
da mulher na sociedade é ser professora e o homem se mantendo nos cargos de chefias era superior, cabendo a tarefa de controlar o trabalho das mulheres.

Arce (2001) questiona: Será a mulher é uma educadora nata? O mito da mulher como uma educadora nata, é algo natural ou construído socialmente? A autora trabalha com todo um contexto histórico de como o mito da mulher como uma professora nata foi construído socialmente e reforçados em documentos que servem como base para a educação do Brasil.

Para Araújo e Cunha (2013), os atributos do papel da mulher como mãe foram construídos pela sociedade. Com esse pensamento as autoras trabalham com a ideia de que: "[...] a função materna é exercida por alguém que realiza as atividades de cuidado e com quem a criança possui um vínculo afetivo importante" (FERNANDES apud ARAÚJO, CUNHA, 2013. p.11253). No entanto, entende-se que o sentimento de maternidade pode ser desenvolvido por outra pessoa que não seja a mãe. $O$ cuidado pode ser o mesmo pelo pai ou outro parente que tenha a guarda.

Carvalho (1996), afirma que a feminização do magistério causou muitos efeitos sobre a educação, pois a organização docente de uma professora era totalmente voltada para as atividades que a mulher desenvolvia no seu dia a dia, isto é, a professora era uma segunda mãe. Contudo, como ressalta Apple (1998) o magistério teve um papel importante para a história das mulheres, pois é a partir do trabalho com o magistério que puderam lutar por seus direitos, se politizar, conquistando assim uma profissão que abriu porta para o campo profissional as mesmas.

Diante da análise deste contexto entende-se como foi o desenrolar desse fenômeno, mas ao mesmo tempo, existem muitas lacunas e questões. Uma delas é: O magistério, ou melhor, a pedagogia tem espaço para o homem no campo da Educação Infantil ou Anos Iniciais? Para entender este contexto, o próximo item buscará referências na atualidade sobre a temática, a fim de superar o preconceito existente na sociedade entre o homem e a pedagogia, que muitas vezes está ligado ao senso comum.

\section{O PROFESSOR HOMEM NA EDUCAÇÃO INFANTIL E ANOS INCIAIS: CONCEPÇÕES E IDEIAS CORRENTES}

Como apontado no item anterior à educação na fase inicial é realizada normalmente por professoras. Desse modo, vale destacar que essa profissão é entendida por muitos como feminina, isso é, as pessoas “[...] em sua grande maioria, do norte ao sul do país, que a educação infantil é papel/função da (de) mulher" (SILVA, VELOSO, 2018. p. 2). Esse pensamento também está presente no ambiente escolar.

Assim, a problemática do homem com a pedagogia e o trabalho com a Educação Infantil e nos Anos Iniciais precisa ser repensado por gestores educacionais, sendo necessário discussões e reflexões sobre essa temática, para que se supere esse preconceito dentro e fora do ambiente 
escolar. Com base nos estudos de Silva (2014) entende-se que a mulher como carinhosa, afetiva, com o dom de ensinar com amor foi construído socialmente, bem como a figura do homem sempre ligada ao poder também foi uma construção social ao longo da história.

Como foi dito no item anterior, é preciso lembrar que os primeiros professores foram homens e assim, permaneceu por muito tempo, mas vale ressaltar que com as transformações a qual a nossa sociedade passou, fez com que o homem se afastasse das relações da educação. Souza (2015) aponta vários fatores fizeram com que o homem abandonasse a educação, entre eles o a desvalorização da profissão, que acarretou baixos salários e nas péssimas condições de trabalho.

Outra hipótese para se desvendar o porquê o homem abandonou a educação, pode ser o pensamento da construção de uma família patriarcal, que fez com que o homem se afastasse dos cuidados com a criança, pois essa era de total responsabilidade da mulher. O homem deveria sustentar a família e precisava de uma profissão rentável. Dessa forma, com esse pensamento enraizado na sociedade, a mulher assume como protagonista a função de cuidar e educar os filhos.

O cuidar e educar está previsto em vários documentos da Educação Infantil, o que faz com que o trabalho docente se caracterize como algo extremamente ligado ao feminino. Monteiro e Altmann (2014) destaca que há um número de homens que ingressam na carreira docente para se dedicar ao trabalho com a Educação Infantil e Anos Iniciais, mas essa ainda é apenas uma pequena parcela.

Outro fator ressaltado por Monteiro e Altmann (2014) é que "[...] os homens que atuam como professores de educação infantil se depararam com outro questionamento quanto à sua orientação sexual" (MONTEIRO, ALTMANN. 2014. p. 732). Dessa forma, ao se dedicar a uma profissão considerada feminina pela sociedade, os professores que optam por trabalhar com a docência tem sua masculinidade questionada por estarem em um trabalho que necessita desenvolver sentimentos, carinho e cuidados pelas e para as crianças.

Partindo desta discussão sobre os questionamentos da masculinidade, entende-se que as escolas reproduzem o que está na sociedade. Este pensamento segundo Monteiro e Altmann (2014, p. 737) se traduz em um conceito “[...] vulnerável, pois revela um ideal impossível de virilidade, em que os jogos e esportes violentos são formas de produzir uma noção visível dessa masculinidade". Esse pensamento de que o homem é detentor de força e poder, fez reforçar a ideia de que pode ser uma autoridade na escola, que consegue resolver os problemas causados pela indisciplina dos alunos. Vale destacar aqui que essa visão não é verdadeira, pois a mesma reforça a imagem do homem como figura de autoridade que consegue resolver todos os problemas com o seu poder de liderança, mas não é assim que acontece.

Existe também a polêmica com a preocupação de "[...] pais, gestores escolares e até dos próprios professores homens, é em relação ao contato físico do docente do gênero masculino com o corpo da criança" (GONÇALVES et al. 2015. p. 144). Ou seja, o toque e o contato físico entre professor/aluno abre espaço para uma desconfiança do profissionalismo do homem 
enquanto professor, levando a se pensar até em abuso sexual infantil. Entende-se a "[...] pedofilia como uma das suas justificativas de resistência à presença de professores homens na educação infantil" (SILVA, VELOSO, 2018. p. 9).

É preciso refletir acerca destas constatações com cuidado, como destacam Campos et al. (1991) o toque e a interação entre os pares acontece na escola, mas a interação mulher/criança é mais aceita do que a interação homem/criança.

É como se a maternidade efetiva ou potencial de qualquer mulher impedisse, ou bloqueasse, a erotização de suas interações com a criança. As imagens de inocência e pureza ligadas à maternidade não parecem extensivas à paternidade. Quando homens se dedicam ao trabalho educativo com crianças pequenas passam a ser suspeitos tanto sobre sua identidade masculina, quanto sobre sua moralidade (CAMPOS et al., 1991, p. 55).

Partindo desse pressuposto entende-se que o homem, quando assume sua cadeira na Educação Infantil ou nos Anos Iniciais, é questionado sobre sua orientação sexual, sobre o seu profissionalismo e até mesmo sobre a sua moral. De acordo com Monteiro (2014) um homem, ao escolher ser professor da Educação Infantil ou dos Anos Iniciais na atualidade está quebrando paradigmas:

Dessa maneira, optar por uma carreira considerada socialmente como 'feminina' se mostrou como um 'sinal' de "atravessamento de 'fronteiras' e, dessa forma, a orientação sexual dos professores foi questionada, fosse durante os cursos de formação inicial, ou mesmo no decorrer de suas trajetórias docentes (MONTEIRO, 2014. p. 89).

Nesse sentido a chegada do homem na educação é um ponto positivo, pois o mesmo pode ser um exemplo para os alunos. Para Gonçalves et al. (2015) o professor homem é importante para a educação "[...] para que sejam modelos positivos de masculinidade e ainda contribuir com a existência de diversidade e equidade de gênero na educação" (GONÇALVES et al., 2015).

Sobre os cuidados com a criança na Educação Infantil e Anos Inicias, vale destacar que o pensamento predominante é que a professora deve "[...] ser mais cuidadoras, mais afetuosas; veem, assim, as instituições de ensino para crianças como uma extensão do lar" (SILVA, VELOSO. 2018. p.2). Ou seja, o cuidar e o educar presente o tempo todo, pois a escola é pensada como a extensão da casa da criança e a professora como sua parente, alguém próximo, por exemplo, quando chamam a professora de tia. Silva (2014) rebate essas afirmações questionando alguns pontos:

O professor/ a professora de educação infantil não é um cuidador ou cuidadora, nem babá, como alguns pais se referem ainda. Ele / ela é alguém que exerce uma profissão. Recebeu formação para isso. Foi aprovado num concurso público ou passou por uma entrevista que o habilita a exercer uma função: a função de ensinar na primeira infância. Referimo-nos, portanto, a uma pessoa 
que trabalha. Está envolvida em práticas de ensino e aprendizagem, cuidado e desenvolvimento humano (SILVA, 2014, p.40).

A partir dessa reflexão, entende-se que o professor ou a professora são habilitados para trabalhar com a educação, pois possuem uma formação profissional que garante sua atuação, portanto, todos devem ser valorizados como tal. Se a sociedade como um todo sinaliza o receio com o professor em sala de aula, mas é preciso lembrar que esse profissional teve um processo de formação acadêmica que envolve teoria e prática, passou por um processo de seleção (concurso) que comprova que o mesmo está apto a desenvolver as atividades docentes com as crianças.

Souza (2015) em seu artigo muda o foco da discussão realizada até o momento, e questiona como as crianças veem a participação do homem como professor e se em sala de aula eles preferem um professor ou professora? $\mathrm{O}$ autor aponta que os resultados dessa pesquisa demonstram que os alunos escolheram o profissional a partir da experiência positiva ou negativa que cada um teve com o professor independente do gênero dentro da fala de aula. Contudo vale destacar que as crianças são protagonistas das práticas pedagógicas que elas estão inseridas.

De acordo com Gonçalves et al. 2015. p.150 "[...] o acesso de docentes do gênero masculino no ensino fundamental e médio é bem mais acolhido e aceito pela sociedade na atualidade.” Enquanto na Educação Infantil e Anos Inicias a resistência do homem como professor ainda é muito grande, pois como foi dito, muitos pais e até mesmo os profissionais da educação tem mais confiança no trabalho por uma professora do que o desenvolvido pelo professor.

Diante do exposto, entende-se que o professor homem na Educação Infantil e Anos Inicias, é um tema que precisa ser discutido. Vale aqui destacar que esses profissionais passaram por um processo de formação com teoria e prática e independente do gênero estão preparados para desenvolver o trabalho com a docência na área que preferir.

\section{CONSIDERAÇÕES FINAIS}

Ao final deste estudo entende-se que a participação da mulher na pedagogia e o seu papel enquanto professora nata, que possui o dom de ensinar a criança, foi construído historicamente. No advento da Pedagogia, o homem tinha um papel importante na construção do conhecimento das crianças, com as mudanças da sociedade, esse papel foi se perdendo ao longo do tempo, e o homem se distanciou da pedagogia para buscar outras profissões.

$\mathrm{O}$ abandono do homem para com a pedagogia abriu espaço para que as mulheres se destacassem na conquista de uma profissão ser professora. Sendo assim, esse passo foi fundamental para que a partir dessa profissão as mulheres lutassem pelos seus direitos. Porém 
vale destacar que o fato das mulheres dividirem seu tempo entre as atividades domésticas e sua atuação docente repercutiu para que a professora fosse vista como uma segunda mãe.

Conclui-se que o papel do homem como professor na Educação Infantil e Anos Iniciais é uma temática que na atualidade precisa ser repensada, dessa forma, é preciso abrir discussões entre professores, gestores e comunidade escolar para que essas reflexões contribuam para combater o preconceito existente na sociedade. É necessário entender que a sociedade está em constante transformação e não é possível limitar apenas a definição do que é um trabalho de homem ou de mulher ou se o homem pode ou não ser professor. Objetivo principal de toda a discussão sobre educação precisa ser em torno de colo elaborar questões didáticas que contribuem para a aprendizagem dos alunos.

Ao final deste estudo, conclui-se que o diálogo e o debate sobre o papel do homem enquanto professor da Educação Infantil e Anos Iniciais na sociedade atual é uma das melhores formas para superar o preconceito que foi construído ao longo da história. Ser professor não é algo pronto e acabado, mas sim fruto de um processo de formação. Nesse sentido é necessário continuar com outros estudos referentes à temática.

\section{REFERÊNCIAS}

Agência Brasil. < https://agenciabrasil.ebc.com.br/geral/noticia/2017-03/mulheres-trabalham75-horas-mais-que-homens-devido-dupla-jornada > acesso em 15/11/2020.

ABBAGNANO, Nicola. DICIONÁRIO DE FILOSOFIA. São Paulo:Martins Fontes, 2007.

ARANHA, Maria Lúcia de Arruda. História da educação e da pedagogia: geral e brasil . 3 ed. rev e ampl. SP: Moderna, 2006.

APPLE, Michael. Ensino e trabalho feminino: uma análise comparativa da história e da ideologia. Cadernos de Pesquisa, nº 64, p. 14-23, São Paulo, fev, 1998.

ARCE, Alessandra. Documentação oficial e o mito da educadora nata na educação infantil.

Cadernos de Pesquisa. São Paulo, n.113, jul. 2001.

ARCE, Alessandra. Friedrich Froebel: o pedagogo dos jardins-de-infância. Petrópolis: Vozes, 2002.

ARAÚJO, Lucélia Costa; CUNHA, Renata Cristina da. Os homens na docência e a feminização do magistério. In: XI Congresso Nacional de Educação - EDUCERE. II Seminário

Internacional de Representações Sociais, Subjetividade e Educação - SIRSSE. IV

Seminário Internacional Sobre Profissionalização - SIPD/CÁTEDRA UNESCO, 23., 2013, Curitiba. Anais [...] . Curitiba: Editora Champangat, 2013. v. 1, p. 11245-11258.

BOTO, Carlota. Civilizar a infância na Renascença: estratégia de distinção de classe. Caderno da pedagogia. ano I Volume 01 Janeiro/Julho de 2007.

A invenção do Emílio como conjectura: opção metodológica da escrita de Rousseau. In:

Educação e Pesquisa. São Paulo, v. 36, n.1, p.207-225. jan/abri. 2010. 
CAMPOS, MARIA M.; GROSBAUM, MARTA; PAHIM, REGINA; ROSEMBERG, FÚLVIA. PROFISSIONAIS DE CRECHE. CADERNOS DO CEDES, N. 9, P. 39-66, 1991.

CARVALHO, Marília Pinto de. Trabalho docente e relações de gênero: algumas indagações. Revista Brasileira de Educação.n. 2, p. 77-84 , Mai/Jun/Jul/Ago, 1996.

DEMARTINI, Zeila de Brito Fabri; ANTUNES, Fatima Ferreira. MAGISTÉRIO PRIMÁRIO: profissão feminina, carreira masculina. Cad. Pesq, n.86. p. 5-14, ago. 1993.

DINIZ, Rosimeire Ferreira; BATISTA, Gustavo Araújo; BERNARDES, Sueli Teresinha de Abreu. AS CONTRIBUIÇÕES DE JEAN-JACQUES ROUSSEAU NA

EDUCAÇÃO. Cadernos da Fucamp, v. 17, n. 30, p. 87-94, 2018.

GONÇALVES, Josiane Peres; CAPRISTO, Zenaide Ribeiro Neto; FERREIRA, Verônica Caroline de Matos. PROFESSORES HOMENS NA EDUCAÇÃO INFANTIL: aceitação e receio dos familiares que vivenciam essa experiência. Pesquisa em Foco, v. 20, n. 2, p. 136154, 29 dez. 2015.

LOCKE, John. De las reconpensas. In: Pensamientos acerca de la educación. Barcelona: Editorial Humanitas, 1982. p. 79-91.

LOURO, Guaciara Lopes. Gênero, sexualidade e educação: uma perspectiva pósestruturalista. Petrópolis, RJ: Vozes, 1997.

MONTEIRO, Mariana Kubilius. TRAJETÓRIAS NA DOCÊNCIA:: professores homens na educação infantil. 2014. 152 f. Dissertação (Mestrado). Faculdade de Educação, Universidade Estadual de Campinas, Campinas, 2014.

MONTEIRO, Mariana Kubilius; ALTMANN, Helena. Homens na educação infantil: olhares de suspeita e tentativas de segregação. Cadernos de Pesquisa, [S.L.], v. 44, n. 153, p. 720-741, set. 2014.

Phelipe, André. Barbosa, Marina. Mulheres são responsáveis pela renda familiar em quase metade das casas.

<https://www.correiobraziliense.com.br/app/noticia/economia/2020/02/16/internas econo mia,828387/mulheres-sao-responsaveis-pela-renda-familiar-em-quase-metade-dascasa.shtml> acesso em 20/10/2020.

ROUSSEAU, J.J. Emílio ou Da Educação. São Paulo: DIFEL, 1995.

SANTOS, Marcos Pereira. O DITO, O ESCRITO E O FEITO: panorama das funções do escravo pedagogo ao pedagogo generalista na história da educação escolar. Revista Científica Intelletto, v. 2, n. 1, p. 64-78, 30 ago. 2017.

SILVA, C. R. Docência masculina na educação infantil: impressões de um iniciante. Gênero e raça em discussão. Jundiaí, SP: Paco Editorial, 2014.

SILVA, Claudionor Renato da; VELOSO, Luana Alves Porto. DESAFIOS DO PROFESSOR HOMEM NA EDUCAÇÃO INFANTIL: um debate a partir do estágio em pedagogia. Itinerarius Reflectionis, v. 14, n. 1, p. 01-14, 10 mar. 2018. 
SOUSA, J. E. . HOMEM DOCÊNCIA COM CRIANÇAS PEQUENAS: o olhar das crianças de um centro de educação infantil. In: $37^{\mathrm{a}}$ Reunião Anual da ANPED, 2015, Florianópolis. Anais [...] da $37^{a}$ Reunião Anual da ANPED, 2015.

Recebido em: 05/01/2022

Aprovado em: 08/02/2022

Publicado em: 12/02/2022 